\title{
ASSESSING THE INTEGRATION OF TRANSPORT SYSTEM: A TOTAL TRAVEL TIME APPROACH
}

\author{
Muhammad Haroon ${ }^{1}$, Amer Aziz ${ }^{2}$ \\ ${ }^{1,2}$ Department of City \& Regional Planning, University of Engineering and Technology, Lahore, Pakistan
}

Received 3 February 2020; accepted 28 April 2020

\begin{abstract}
Total travel time from origin to destination determines convenience of public transport system because reliability of total travel time link with public transport. To better serve the needs of people and to decrease travel time, the flexible solutions for public transport system are growing. One such flexible solution is integration of transportation system. The focus of this research is to measure factors that contribute to total travel time. Six major road of Peshawar city are studied to collect data regarding access time, egress time, waiting at transit stop and walking time while mode shifting. Hypothetically significance measured of these four different times upon total travel time to assess transport integration system. The analysis shows that multi-modal public transport trips effect total travel time because, waiting and extra walking time exists in mode transfer. Access and egress times don't have any positive significance with total travel time because access and egress times are considered part of travel time.
\end{abstract}

Keywords: total travel time, transport integration, access time, egress time, waiting time, walking time.

\section{Introduction}

The rapid urbanization in developing countries over the past half-century seems high level of intensity of urban population (Henderson, 2002). In 1950, 29.6\% population of globe was living in urban area while now this number has increased to $54 \%$ almost double to half-century before and still increasing (UN-Habitat, 2015). Over the next 30 years, it is expected that world population is concentrated towards urban areas, especially in developing countries (Cohen, 2006). Increasing urban population needs integrated transport system to enhance their mobility

${ }^{1}$ Corresponding author: plnrharoon123@hotmail.com because mobility is important component of life in cities across the world. People need mobility and accessibility to satisfy their needs (Alsnih and Hensher, 2003). Mobility is highly influenced by traffic congestion, which is a major problem all around the world, it is wastage of time, missed of opportunities and a factor of frustration (Wen, 2008). An effective integration transport system is necessary for a city. Link to the primary and secondary routes through effective transport system is necessary because travel timing, travel cost, convenience of travel etc. are important factors and are affected by traffic congestion (Kok et al., 2012). 


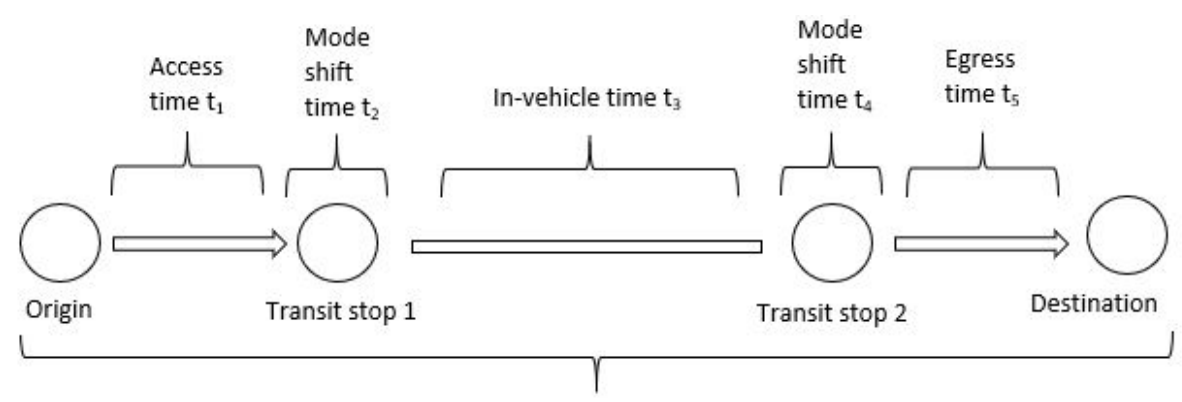

Total travel time T

Fig. 1.

Transport Chain Origin to Destination

Source: Conceptual Sketch by Researcher to Explain Time Distribution between Origin and Destination

$T=t_{1}+t_{2}+t_{3}+t_{4}+t_{5}$

Transport integration can be defined as "It is the process through which different planning and delivery of elements of transportation system are taken in consideration such as modes (motorized and non-motorized), sectors, operators and institution with aim of increasing social benefits (NEA, OGM, and TSU, 2003). The transport network is the combination of different links in transport chain from origin to destination, combining of different networks form a new integrated transport system and this integration entails through transport links with different modes of transport (Brand, 2015). Integration become important phenomena when system depends upon different integration approaches, such as, Institutional integration, Physical integration, information integration and Transport network integration but each approach needs the complementation with each other for the system to work efficiently (Givoni and Banister, 2010). Effective transport integration system has the characteristics of accessibility, intermodal connectivity, multi-modal mobility and also present a transport chain for entire trip from origin to destination (Brand et al., 2017). One trip from origin to destination is consist of multi-modal transfer from origin to destination known as multimodal trip. Multi-modal trip is the use of two or more transport services for making a trip (Van Nes, 2002). Travel becomes more comfortable and time saving from origin to destination if system well integrated. Mobility and accessibility from one place to another through improved integration of public transport modes can reduce total travel cost, travel time and inconvenience (Aziz et al., 2018). Many researchers work on total travel time variation/deviation from origin to destination and studied different parameters ( $\mathrm{Wu}$ and Geistefeldt, 2014; Brownstone and Small, 2005; Lint et al., 2008; Sweet and Chen, 2011; Peer et al., 2012).

Non-integrated transport network has major concerned with total travel time because, in multi-modal trip there is multiple time phases are existing. Figure 1 express all time phases from origin to destination. Such as, access time, walking time, in-vehicle time and egress 
time. All these different time phases combine and make total travel time between origin and destination (Eq. (1)). While using multimodal public transport these are consider weakest part of travel and had significant impact on total travel time (Bovy and Jansen, 1979; The Central Transportation Planning Staff, 1997) The in-vehicle time is somehow constant (Garcia-Martinez et al., 2018), but walking time, access time and egress time have major impact upon the total travel time. Walking time consist of waiting time and extra walking time. When someone arrives at transit stop and does not have any proper information regarding arrival of next vehicle and wait for arrival of vehicle. Similarly walking to transit stop because there is no mode shift near transit stop and walk to transit stop to capture next vehicle. These two phases of time have high impact upon total travel time. The access from origin to first transit stop and egress from second transit stop to destination, both have the reasonable quantity of time to impact total travel time.

Many researchers investigated the perception of mode transfer impact on total travel time (Navarette and Ortuzar, 2013; Chowdhury et al., 2014; Guo, 2003) stated that waiting and walking time to next mode has significant impact on travel time. In ideal situation of mode transfer these two types of times are consider zero and other related factors such as, safety, comfort, security, availability of information regarding headway/arrival of next vehicle, etc, (Douglas, 2013), this is known as pure transfer penalty (GarciaMartinez et al., 2018). The time from home or origin to first transit stop (access time) and then from second transit stop to work or destination (egress time) strongly associated with total travel time and has significant impact (Krygsman et al., 2004).
The purpose of this paper is to explore following hypothesis about total travel time, access time, egress time, walking time and waiting time at transit stop:

- Hypothesis 1: There is no association between the number of modes used for travel and total travel time;

- Hypothesis 2: walking and waiting time have no influence on total travel time;

- Hypothesis 3: The access and egress time to and from transit stop reveal similar walking and waiting time for total travel time.

\section{Methodology}

This study is conducted in Peshawar urban area: the capital city of Khyber Pakhtunkhwa Province of Pakistan. The total urban population according to 2017 census report is 1,970,042 (Khan and Ali, 2019). Peshawar is linear urban form people who live at outskirt of city commute to city on daily basis and become the reason of different traffic problems, traffic congestion is one of severe problem out of them (Ali et al., 2012). The nature of this research is purely quantitative. The data used in this research comes through field survey undertaken six major roads of Peshawar. Within selected roads questionnaires are filled from daily travelers over the age of 15 years and use multi-modal Public Transport. A total of 204 (34 from each road) respondents are selected (stratified sample) through Eq. (2) Kohran's formula (Altares et al., 2003), with margin of error $7 \%$. Statistical Package for Social Sciences (SPSS) software used to analyze survey results.

$\mathrm{n}=\mathrm{N} / 1+\mathrm{Ne}^{2}$ 
where $\mathrm{n}$ is sample size, $\mathrm{N}$ is total urban population and e is margin of error.

\section{Analysis}

Collected data analyzed for testing research hypothesis. Hypothesis are tested based on different factors impact on total travel time.

\subsection{Testing of Hypothesis 1}

People in Peshawar mostly use multi-modal public transport from origin to destination and go through multiple time phases due to total travel time effected. Total travel time and number of modes used one-way trip has association or not is tested through chi-square test from collected data. Crosstabulation between two variables of field survey used to determine the relative association of each variable.

Cross tabulation in Table 1 shows that there is more travel time if one use multi-modal transport. The observed values are extracted through the frequencies of variables and expected values can be collected through.

$\mathrm{E}=$ sum of row $\mathrm{x}$ sum of column/ Grand total.

\section{Table 1}

Cross Tabulation between Number of Modes Used (OD) and Total Travel Time

\begin{tabular}{|c|c|c|c|c|c|c|c|}
\hline \multirow{2}{*}{\multicolumn{2}{|c|}{ Number of modes }} & \multicolumn{5}{|c|}{ Total travel time (Minutes) } & \multirow{3}{*}{$\begin{array}{c}\text { Total } \\
57 \\
\end{array}$} \\
\hline & & \multirow{2}{*}{$\begin{array}{c}\mathbf{1 - 3 0} \\
10 \\
\end{array}$} & \multirow{2}{*}{$\begin{array}{c}31-45 \\
23 \\
\end{array}$} & \multirow{2}{*}{$\begin{array}{c}46-60 \\
13 \\
\end{array}$} & \multirow{2}{*}{$\frac{61-75}{8}$} & \multirow{2}{*}{$\begin{array}{c}\text { Above } \mathbf{7 6} \\
3\end{array}$} & \\
\hline & Observed & & & & & & \\
\hline 1 & Expected & 3.4 & 10.1 & 18.7 & 18.7 & 6.1 & 57 \\
\hline \multirow{2}{*}{2} & Observed & 2 & 11 & 38 & 15 & 7 & 73 \\
\hline & Expected & 4.3 & 12.9 & 24 & 24 & 7.9 & 73 \\
\hline \multirow{2}{*}{3} & Observed & 0 & 2 & 16 & 44 & 12 & 74 \\
\hline & Expected & 4.4 & 13.1 & 24.3 & 24.3 & 8 & 74 \\
\hline
\end{tabular}

Source: Research study

In order to check significance association between the attributes, observed and expected or theoretical frequencies grouped in following Chi-square distribution formula (Kothari, 2004, Eq. (3)).

$x^{2}=\sum_{i=1}^{r} \sum_{J=1}^{c} \frac{\left(o_{i j}-E_{i j}\right)^{2}}{E_{i j}}$

where:

$\mathrm{X}^{2}=$ Chi-square distribution;

$\mathrm{O}_{\mathrm{ij}}=$ Observed frequency $i^{\text {th }}$ row $\& j^{\text {th }}$ column;

$\mathrm{E}_{\mathrm{ij}}=$ Expected frequency $i^{\text {th }}$ row $\& j^{\text {th }}$ column. 
The chi-square test is used to determine the association between the variables under observation. To perform chi-square test with degree of freedom (d.f) 8 (Eq. (4)). The calculated value of Chi Square is 85.31 (Table 2). Compare this calculated value to chi-square distribution Table 7 (Appendix 1) with confidence level of $0.1,0.05$ and 0.025 that are $13.36,15.51$ and 17.53 respectively. All values are less than the calculated values.
Therefore, null hypothesis is rejected, and it is proved that there is strong association between number of modes used in one-way trip with total travel time.

Degree of freedom $=(\mathrm{r}-1)(\mathrm{c}-1)=(3-1)(5-1)=8$

where:

$\mathrm{r}=$ number of rows in cross-tabulation;

$c=$ number of columns in cross-tabulation.

Table 2

Chi-Square Test

\begin{tabular}{|c|c|c|c|c|}
\hline Observed $(\mathbf{O})$ & Expected $(\mathbf{E})$ & $(\mathbf{O}-\mathbf{E})$ & $(\mathbf{O}-\mathbf{E})^{2}$ & $(\mathbf{O}-\mathbf{E})^{2} / \mathbf{E}$ \\
\hline 10 & 3.4 & 6.6 & 43.56 & 12.81 \\
\hline 2 & 4.3 & -2.3 & 5.29 & 1.23 \\
\hline 0 & 4.4 & -4.4 & 19.36 & 4.4 \\
\hline 23 & 10.1 & 12.9 & 166.4 & 16.47 \\
\hline 11 & 12.9 & -1.9 & 3.61 & 0.27 \\
\hline 2 & 13.1 & -11.1 & 123.21 & 9.40 \\
\hline 13 & 18.7 & -5.7 & 32.59 & 1.73 \\
\hline 38 & 24 & 14 & 169 & 7.04 \\
\hline 16 & 24.3 & -8.3 & 68.89 & 2.83 \\
\hline 8 & 18.7 & -10.7 & 114.47 & 6.12 \\
\hline 15 & 24 & -9 & 81 & 3.37 \\
\hline 44 & 24.3 & 19.7 & 388.09 & 15.97 \\
\hline 3 & 6.1 & -3.1 & 9.61 & 1.57 \\
\hline 7 & 7.9 & -0.9 & 0.81 & 0.10 \\
\hline 12 & 8 & 4 & 16 & 2 \\
\hline$\Sigma \mathrm{O}=204$ & $\Sigma \mathrm{E}=204$ & & & $\mathrm{X}^{2}=85.31$ \\
\hline
\end{tabular}

Source: Research study

\subsection{Testing of Hypothesis 2}

When someone starts to travel from origin, he/she consider total travel time budget which the travelers have for specific trip and traveler does not know the exact travel time from origin to destination. $\mathrm{He} / \mathrm{sh}$ departs earlier for additional time to travel or add marginal time in expected travel time to avoid inconvenience to late arrival (Lo et al., 2006). But this budget time can be affected due to some factors such as, link degradation, walking time, waiting time, reliability of mode arrival etc. these factors need strong consideration to reduce total travel time and bring it with minimum excepted range.

To determine the impact of waiting time and walking time on total travel time in Peshawar case multiple regression analysis is applied. Regression analysis applied between three variables one is dependent (total travel time) and two are predictors (waiting time and walking time). Equation of regression analysis is drawn to measure individually impact of each predictor. 
Table 3

Regression Coefficient

\begin{tabular}{|c|c|c|c|c|c|c|}
\hline & \multirow[t]{2}{*}{ Model } & \multicolumn{2}{|c|}{ Unstandardized Coefficients } & \multirow{2}{*}{$\begin{array}{c}\begin{array}{c}\text { Standardized } \\
\text { Coefficients }\end{array} \\
\text { Beta } \\
\end{array}$} & \multirow[t]{2}{*}{$\mathbf{t}$} & \multirow[t]{2}{*}{ Sig. } \\
\hline & & B & Std. Error & & & \\
\hline \multirow{3}{*}{1} & (Constant) & .352 & .124 & & 2.837 & .005 \\
\hline & Walking time & 1.112 & .063 & .642 & 17.689 & .000 \\
\hline & Waiting time at junction & .730 & .061 & .432 & 11.908 & .000 \\
\hline
\end{tabular}

Source: Research study

Table 3 explain relative importance of each predicting variable and also describe about the significance of model here $p$ value is less than 0.05 . So, model is significant and null hypothesis is rejected. To measure relative impact of each variable regression equation that describe relative impact is developed.

$\mathrm{Y}=\mathrm{b}_{0}+\mathrm{b}_{1} \mathrm{X}_{1}+\mathrm{b}_{2} \mathrm{X}_{2}$

$\mathrm{Y}=0.352+1.112$ (walking time) +0.730

(waiting time at junction)
Eq. (5) determines the coefficient of both predictors.

From multiple regression analysis it is noted that waiting time and walking in Peshawar transport network system has great impact upon total travel time. Waiting time and walking time can be reduced through effective integration system. Access from origin (home) to transit stop and wait for arrival of vehicle is hesitating if no proper information available.

\section{Table 4}

Regression Model Summary

\begin{tabular}{|c|c|c|c|c|}
\hline Model & R & R Square & Adjusted R Square & Std. Error of the estimate \\
\hline 1 & $.915^{\mathrm{a}}$ & .837 & .835 & .349 \\
\hline
\end{tabular}

Source: Research study

In the above Table $4, \mathrm{R}$ is the correlation between observed and predicted values of dependent. Absolute value of $\mathrm{R}$ represents the strength of relationship. R Square describe the proportion of variation in the dependent variable and ranges from 0 to 1 . How much R square value near 1 it represents good model of fitness (Montgomery et al., 2012). The value of $R$ Square is .837 which is close to 1 . Therefore, it is good model of fitness. So, waiting time and walking have significance variation in total travel time.

\subsection{Testing of Hypothesis 3}

The access and egress time are considered important time components in multi-modal Public Transport. To measure significance of predictor (access and egress time) in dependent (total travel time) in Peshawar, multiple regression analysis performed.

Table 5 explain relative influence of each variable on dependent. The $\mathrm{p}$ value for both access time and egress time is greater than 
0.05 therefore, this model is not significant and shows that access and egress time do not have any impact upon total travel time and the hypothesis is rejected.

Generally, the variance in total travel time due to access and egress time is very low it is previously researched by different researchers (Levinson and Kumar, 1997; Ortuzar and Willumsen, 2002). In Peshawar point of view it is also proved that access and egress time do not have any variance in total tarvel time.

Table 5

Regression Coefficient

\begin{tabular}{|c|c|c|c|c|c|}
\hline \multirow{2}{*}{ Model } & \multicolumn{2}{|c|}{ Unstandardized Coefficient } & $\begin{array}{c}\text { Standardized } \\
\text { Coefficient }\end{array}$ & \multirow{2}{*}{ t } & \multirow{2}{*}{ Sig } \\
\cline { 2 - 5 } & $\mathbf{B}$ & Std. Error & Beta & & \\
\hline Constant & 3.459 & .217 & & 15.950 & .000 \\
\hline Access time & -.072 & .065 & -.078 & -1.107 & .270 \\
\hline Egress time & -.023 & .067 & -.024 & -.339 & .735 \\
\hline
\end{tabular}

Source: Research study

\subsection{Response Analysis}

The survey results describe that in Peshawar average total travel time is 70 minutes. Access and egress time are the part of time that are mostly depends upon different components of catchments. The Table 6 shows the average of different time duration between origin and destination in context of Peshawar urban area.

Table 6

Mean Values of Different Time Phases Between Origin and Destination

\begin{tabular}{|c|c|c|c|c|c|}
\hline \multirow{2}{*}{$\begin{array}{l}\text { Waiting time at } \\
\text { transit stop }\end{array}$} & \multirow[b]{2}{*}{ Walking time } & \multicolumn{3}{|c|}{ In-vehicle time } & \multirow{2}{*}{$\begin{array}{l}\text { Total travel } \\
\text { time }\end{array}$} \\
\hline & & Access time & Agress time & $\begin{array}{c}\text { Public bus } \\
\text { time }\end{array}$ & \\
\hline 8 minutes & 5 minutes & 12 minutes & 11 minutes & 37 minutes & 70 minutes \\
\hline
\end{tabular}

Source: Research study

\section{Conclusion and Discussion}

The average waiting time at transit stop is 8 minutes and extra walking time is 5 minutes. These times are too much to effect total travel time. Access and egress times are considered in-vehicle time because these are the part of travel time. Access and egress time effected by distance, mode of transport, urban density, demography and physical location of catchment (Krygsman et al., 2004).
Testing of hypothesis 1 proved that there is a strong relationship between total travel time and multi-modal public transport used between origin and destination because in multi-modal public transport there is extra waiting and wallking time.

Testing of hypothesis 2 proved that the waiting at transit stop and walking time while mode shifting has significant impact upon total travel time and has high coefficient of impact (Eq. (5)). Waiting and walking times 
determines convinience and potential of public transportation system. Integrated transport system (information \& physical integration) that can reduce these time upto minimum possible limit. For information, the real time information display at stop and pamphlets at each transit stop can provide information about public transport headway, route, location of vehicle etc. the real time information display is used all around the world it easy to install but operation and maintainess cost is high (Yeung, 2004). The proper mode shift or parking near transit stop that people can use for Park \& Ride purpose (if someone use private vehicle for access) and easy transfer.
Testing of hypothesis 3 proved that access and egress time do not have any impact upon total travel time. These are considered the part of total travel time if someone use multimodal public transport. Rietveld (2000) argues that impact of access and egress time is associated with access and egress distance and considered very low (Rietveld, 2000).

It is concluded that there is no concept of public transport integration system in Peshawar. Averge travel time between origin and destination is 70 minutes. There is a need for effective integration system to enhance mobility, increase accessibility and human satisfaction with integrated public transport system.

\section{Appendix 1}

\section{Table 7}

Chi-Square Distribution Table

\begin{tabular}{|c|c|c|c|c|c|c|c|c|c|}
\hline d.f & $\mathbf{. 9 9 5}$ & $\mathbf{. 9 9}$ & $\mathbf{. 9 7 5}$ & $\mathbf{. 9 5}$ & $\mathbf{. 9}$ & $\mathbf{. 1}$ & $\mathbf{. 0 5}$ & $\mathbf{. 0 2 5}$ & $\mathbf{. 0 1}$ \\
\hline 1 & 0.00 & 0.00 & 0.00 & 0.00 & 0.02 & 2.71 & 3.84 & 5.02 & 6.63 \\
\hline 2 & 0.01 & 0.02 & 0.05 & 0.10 & 0.21 & 4.61 & 5.99 & 7.38 & 9.21 \\
\hline 3 & 0.07 & 0.11 & 0.22 & 0.35 & 0.58 & 6.25 & 7.81 & 9.35 & 11.34 \\
\hline 4 & 0.21 & 0.30 & 0.48 & 0.71 & 1.06 & 7.78 & 9.49 & 11.14 & 13.28 \\
\hline 5 & 0.41 & 0.55 & 0.83 & 1.15 & 1.61 & 9.24 & 11.07 & 12.83 & 15.09 \\
\hline 6 & 0.68 & 0.87 & 1.24 & 1.64 & 2.20 & 10.64 & 12.59 & 14.45 & 16.81 \\
\hline 7 & 0.99 & 1.24 & 1.69 & 2.17 & 2.83 & 12.02 & 14.07 & 16.01 & 18.48 \\
\hline 8 & 1.34 & 1.65 & 2.18 & 2.73 & 3.49 & 13.36 & 15.51 & 17.53 & 20.09 \\
\hline 9 & 1.73 & 2.00 & 2.70 & 3.33 & 4.17 & 14.68 & 16.92 & 19.02 & 21.67 \\
\hline 10 & 2.16 & 2.56 & 3.25 & 3.94 & 4.87 & 15.99 & 18.31 & 20.48 & 23.21 \\
\hline
\end{tabular}

Source: (Steiger et al., 1985)

\section{References}

Ali, Z.; Shah, S.A.A.; Hussain, A. 2012. Growing Traffic in Peshawar: An Analysis of Causes and Impacts, $A$ Research Journal of South Asian Studies 27(2): 409-420.

Alsnih, R.; Hensher, D.A. 2003. The Mobility and Acessibilitly Expectation of Seniors in an aging Polpulation, Sydney: Institute of Transport studies: The Australian Key Centre in Transport management.
Altares, P.S.; Copo, A.R.I.; Gabuyo, Y.A.; Laddaran, A.T.; Mejia, L.D.P.; Policarpio, I.A.; Sy Eag, T.H; Yao, A. 2003. Elementary statistics: a modern approach. Manila, Philippines: Rex, 18.

Aziz, A.; Nawaz, M.S.; Nadeem, M.; Afzal, L. 2018. Examining suitability of the integrated public transport system: A case study of Lahore, Transportation Research Part A: Policy and Practice 117: 13-25. 
Bovy, P.; Jansen, G. 1979. Travel times for disaggregate travel demand modelling: a discussion and a new travel time model. New developments in modelling travel demand and urban systems, Saxon House, England, 129-158.

Brand, J.C. 2015. Assessing integration of bus network with non-motorized Acess and Egress modalitiis, AmstellandMeerlanden: Delft University of Technology.

Brand, J.C. 2015. Assessing Integration of Bus Networks with Non-Motorised Access and Egress Modalities; case study Bus Network Integration with Access and Egress Modalities in Amstelland, Amstel land: Delft University of Technology.

Brand, J.; Hoogendoorn, S.; Oort, N.V; Schalkwijk, B. 2017. Modelling multimodal transit networks integration of bus networks with walking and cycling, Amsterdam, IEEE.

Brownstone, D.; Small, K.A. 2005. Valuing time and reliability: assessing the evidence from road pricing demonstrations, Transportation Research Part A: Policy and Practice 39(4): 279-293.

Chowdhury, S.; Ceder, A.; Sachdeva, R. 2014. The effects of planned and unplanned transfers on public transport users' perception of transfer routes, Transportation Planning and Technology 37(2): 154-168.

Cohen, B.M. 2006. Urbanization in developing countries: Current trends, future projections, and key challenges for sustainability, Technology in society 28(12): $63-80$.

Douglas, N.J.J.M. 2013. Estimating transfer penalties and standardised income values of time by stated preference survey. Australian transport research forum, Australia.

Fan, Y.; Guthrie, A.; Levinson, D. 2016. Waiting time perceptions at transit stops and stations: Effects of basic amenities, gender, and security, Transportation Research Part A: Policy and Practice 88: 251-264.
Garcia-Martinez, A.; Cascajo, R.; Jara-Diaz, S.R.; Chowdhury, S.; Monzon, A. 2018. Transfer penalties in multimodal public transport networks, Transportation Research Part A: Policy and Practice 114: 52-66.

Givoni, M.; Banister, D. 2010. Integrated Transport: from policy to practice, Oxford: Routledge.

Government of ACT. 2015. Building the integrated transport network. Canberra: Winton Sustainable Consultants.

Guo, Z. 2003. Assessment of the transfer penalty to transit trips in Downtown Boston: a GIS-based disaggregate modeling approach, Doctoral dissertation, Massachusetts Institute of Technology, USA.

Habitat, U.N. 2015. International guidelines on urban and territorial planning. United Nations Human Settlements Programme, Nairobi.

Henderson, V. 2002. Urbanization in Developing Countries, The World BankResearch Observer 17(1): 89-112.

Khan, A; Arshad, M.A. 2015. Study of Various Mass Transit Options for Peshawar City by Life Cycle Cost Analysis, In Proceedings of the 1st International Multi-Disciplinary Conference (IMDC), The University of Lahore, Gujrat Campus, PK, 23-24 November, 4p.

Khan, A.; Ali, M. 2019. Impact of Built environment on groundwater depletion in Peshawar, Pakistan, Journal of Himalayan Earth Science 52(1): 86-105.

Kok, A.; Hans, E.; Schutten, J. 2012. Vehicle routing under time-dependent travel times: the impact of congestion avoidance, Computers \& operations research 39(5): 910-918.

Krygsman, S.; Dijst, M.; Arentze, T. 2004. Multimodal public transport: an analysis of travel time elements and the interconnectivity ratio, Transport Policy 11: 265-275. 
Levinson, D.M.; Kumar, A. 1997. Density and the journey to work, Growth and change 28(2): 147-172.

Lint, J.V.; Zuylen, H.J.V.; Tu, H. 2008. Travel time unreliability on freeways: Why measures based on variance tell only half the story, Transportation Research Part A: Policy and Practice 42(1): 258-277.

Lo, H.K.; Luo, X.; Siu, B.W. 2006. Degradable transport network: Travel time budget of travelers with heterogeneous risk aversion, Transportation Research Part B: Methodological 40(9):792-806.

Montgomery, D.C.; Peck, E.A.; Vining, G.G. 2012. Introduction to linear regression analysis. Fourth ed., Vol. 821. John Wiley \& Sons.

Navarette, F.J.; Ortuzar, J. 2013. Subective valuation of the transit transfer experience: the case of Santiago de Chile, Transport Policy 25: 138-147.

NEA; OGM; TSU. 2003. Integration and Regulatory Structures in Public Transport, Brussels: DGTREN.

Ortuzar, J.; Willumsen, L. 2002. Modelling transport. Third ed. West Sussex, England: Wiley.

Peer, S.; Koopsmans, C.C.; Verhoef, E.T. 2012. Prediction of travel time variability for cost-benefit analysis, Transportation Research Part A: Policy and Practice 46: 79-90.

Rietveld, P. 2000. The accessibility of railway stations: the role of the bicycle in The Netherlands, Transportation Research Part D: Transport and Environment 5(1): 71-75.
Steiger, J.H.; Shapiro, A.; Browne, M.W. 1985. On the multivariate asymptotic distribution of sequential chisquare statistics, Psychometrika 50(3): 253-263.

Sweet, M.N.; Chen, M. 2011. Does regional travel time unreliability influence mode choice?, Transportation 38(4): 625-642.

The Central Transportation Planning Staff. 1997. Transfer penalties in urban mode choice modeling. TMIP. United State: US Department of Transportation.

Van Nes, R. 2002. Design of multimodal transport networks: A hierarchical approach, Netherland: DUP Science.

Wen, W. 2008. A dynamic and automatic traffic light control expert system for solving the road congestion problem, Expert Systems with Applications 34(4): 23702381.

Wu, N.; Geistefeldt, J. 2014. Standard Deviation of Travel Time in a Freeway Network-A Mathematical Quantifying Tool for Reliability Analysis. In CICTP 2014: Safe, Smart, and Sustainable Multimodal Transportation Systems, 3292-3303.

Yeung, T. 2004. Editorial to using IT tools to improve service, Public Transportation International 53(6): 2-3. 